\title{
Corrigendum
}

\section{Behavioral and Neural Analysis of GABA in the Acquisition, Consolidation, Reconsolidation, and Extinction of Fear Memory}

Steve R Makkar, Shirley Q Zhang and Jacquelyn Cranney

Neuropsychopharmacology (2012) 37, 1793-1794; doi:10.1038/npp.2012.16

Correction to: Neuropsychopharmacology (2010) 35, 16251652; doi:10.1038/npp.2010.53; published online 21 April 2010
In this article, there is an error in Figure 1. The revised Figure 1 is shown in the next page. 


\begin{tabular}{|c|c|}
\multicolumn{1}{c}{ Day 1 } & Day 2 \\
\hline CS-US Pairing & Brief CS \\
\hline &
\end{tabular}
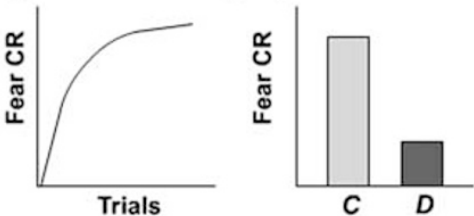

Conditioning

\section{Retention Test}

Acquisition

\section{Retrieval}

\section{Consolidation}
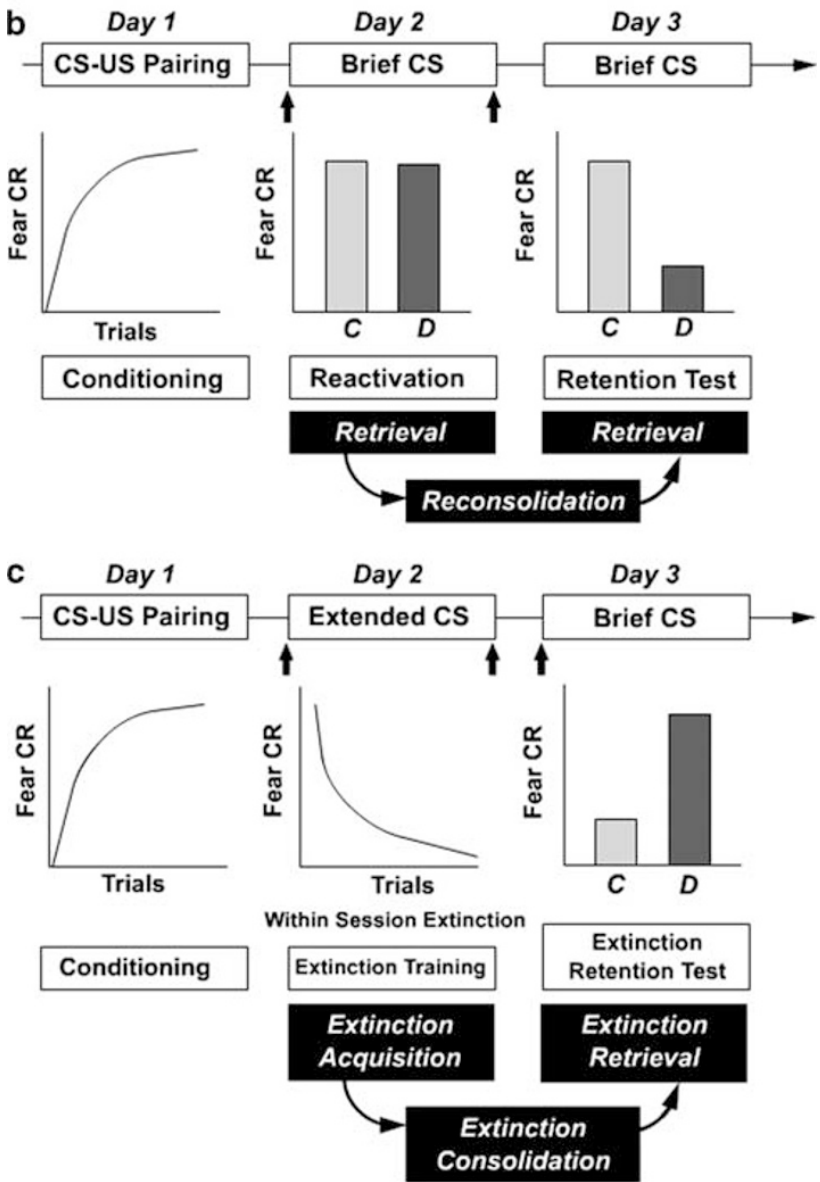